\title{
Entre rosas e ervas: a enigmática figura de Aimé Bonpland (1773-
}

1858)

\author{
Entre rosas y hierbas: la enigmática figura de Aimé Bonpland (1773- \\ 1858)
}

\author{
Among roses and herbs: the enigmatic figure of Aimé Bonpland \\ (1773-1858)
}

\begin{abstract}
Alessandra da Silva ${ }^{1}$
\section{Resumo}

Este estudo consiste em uma análise da biografia do médico botânico francês Aimé Bonpland (1773-1858), e sua viagem sem retorno a América do Sul. Metodologicamente o trabalho foi construído a partir da revisão bibliográfica sobre a temática dos viajantes naturalistas, relatos de viagens e imagens. A análise tem como objetivo compreender o contexto ambiental e político no final do século XVIII e na primeira metade do século XIX, bem como os conflitos envolvendo Aimé Bonpland na fronteira entre Brasil, Paraguai e Argentina.
\end{abstract}

Palavras-chave: Aimé Bonpland.Viajantes naturalistas. América do Sul.

\section{Resumen}

Este estudio consiste en un análisis de la biografía del botánico francés Aimé Bonpland (1773-1858), y su viaje sin regreso a Sudamérica. Metodológicamente el trabajo se construyó a partir de la revisión bibliográfica sobre el tema de los viajeros naturalistas, reportajes de viaje e imágenes. El análisis tiene como objetivo comprender el contexto ambiental y político de finales del siglo XVIII y la primera mitad del XIX, así como los conflictos que involucran a Aimé Bonpland en la frontera entre Brasil, Paraguay y Argentina.

Palabras clave: Aimé Bonpland, viajeros naturalistas. América del Sur.

\begin{abstract}
This study consists of an analysis of the biography of the French botanist Aimé Bonpland (1773-1858), and his journey without return to South America. and images. The analysis aims to understand the environmental and political context in the late 18th century and the first half of the 19th century, as well as the conflicts involving Aimé Bonpland on the border between Brazil, Paraguay and Argentina.
\end{abstract}

Keywords: Aimé Bonpland. Naturalistic travelers. South America.

\section{Introdução:}

\footnotetext{
${ }^{1}$ Doutoranda no Programa de Pós-Graduação em História da UPF; Mestre em Artes Visuais pela UFSM (2019); Universidade de Paço Fundo; Paço Fundo, Rio Grande do Sul, Brasil; ale_s@ unochapeco.edu.br.
} 
A passagem do século de XVIII para o XIX assinala um momento de grandes descobertas científicas. Muitos foram os viajantes financiados por instituições europeias que estiveram no Brasil aprofundando conhecimentos sobre as riquezas naturais, sociais econômicas. No entanto dentre os naturalistas, Aimé Bonpland se destaca trazendo importantes contribuições para a botânica no Rio Grande do Sul não apenas como viajante mas como residente, estudando mais profundamente os aspectos naturais. Seus relatos de viagens, cartas e descrições botânicas são uma fonte riquíssima para estudo em diferentes áreas.

No decorrer desse texto buscamos compreender as motivações que levaram o médico e botânico francês a abandonar um futuro promissor na ciência europeia, por uma vida de reclusão em um cenário de fronteira entre Brasil, Paraguai e Argentina.

\section{A trajetória do médico e botânico Aimé Bonpland}

Aimé Jacques Alexandre Goujaud Bonpland (1773-1858) (conhecido como Aimé Bonplad, Amado Bonpland ou Dom Amado) foi um médico e botânico francês nascido em La Rochele/França, viveu parte de sua vida na América do Sul, na fronteira ente o Brasil, Paraguai e Argentina. Pouco se sabe sobre sua vida antes do encontro com Alexander Von Humboldt (1769-1859) um artista, geógrafo, naturalista alemão. Desde muito jovem se interessou pelas Ciências Naturais, influenciado por seu pai que era cirurgião, estudou anatomia em Paris (1791), aprofundando seus estudos em Botânica e Anatomia. Em 1798 conheceu Humboldt em Paris, onde os mesmos trocaram ideias sobre grandes viagens e pesquisas $^{2}$. Entre os séculos XVIII e XIX, ocorria o período conhecido como "Era de ouro da arte botânica" momento em que artistas habilidosos cruzaram continentes, estudando plantas.

Em um momento em que a produção científica voltava olhares para áreas da medicina e da agronomia, o trabalho de campo envolvendo descrição anatômica e fisiológica desempenhava importante papel, muitas espécies eram coletadas e organizadas nos Jardins Botânicos, transformando-se em importantes materiais de pesquisa e experimentos. Assim os Jardins Botânicos transformaram-se em locais para instruções de boticários, de médicos, de

2ESCOLA, Equipe Brasil. "Aimé Goujaud Bonpland"; Brasil Escola. Disponível em: https://brasilescola.uol.com.br/biografia/aime-goujaud.htm. Acesso em 26 de fevereiro de 2020. 
cirurgiões, de agricultores e, ainda, de grupos de amadores interessados em desenvolver estudos de História Natural.

Nesse cenário, Aimé Bonpland e Alexander Von Humboldt, empreenderam juntos a primeira viagem à América do Sul entre 1799 e 1804 considerada a primeira exploração de uma perspectiva científica dessa região. Visitaram Cuba, atravessaram o centro e o norte dos Andes, o México no intuito de estudar os aspectos físicos da terra, coletar amostras e estudar diversas espécies de plantas e animais.

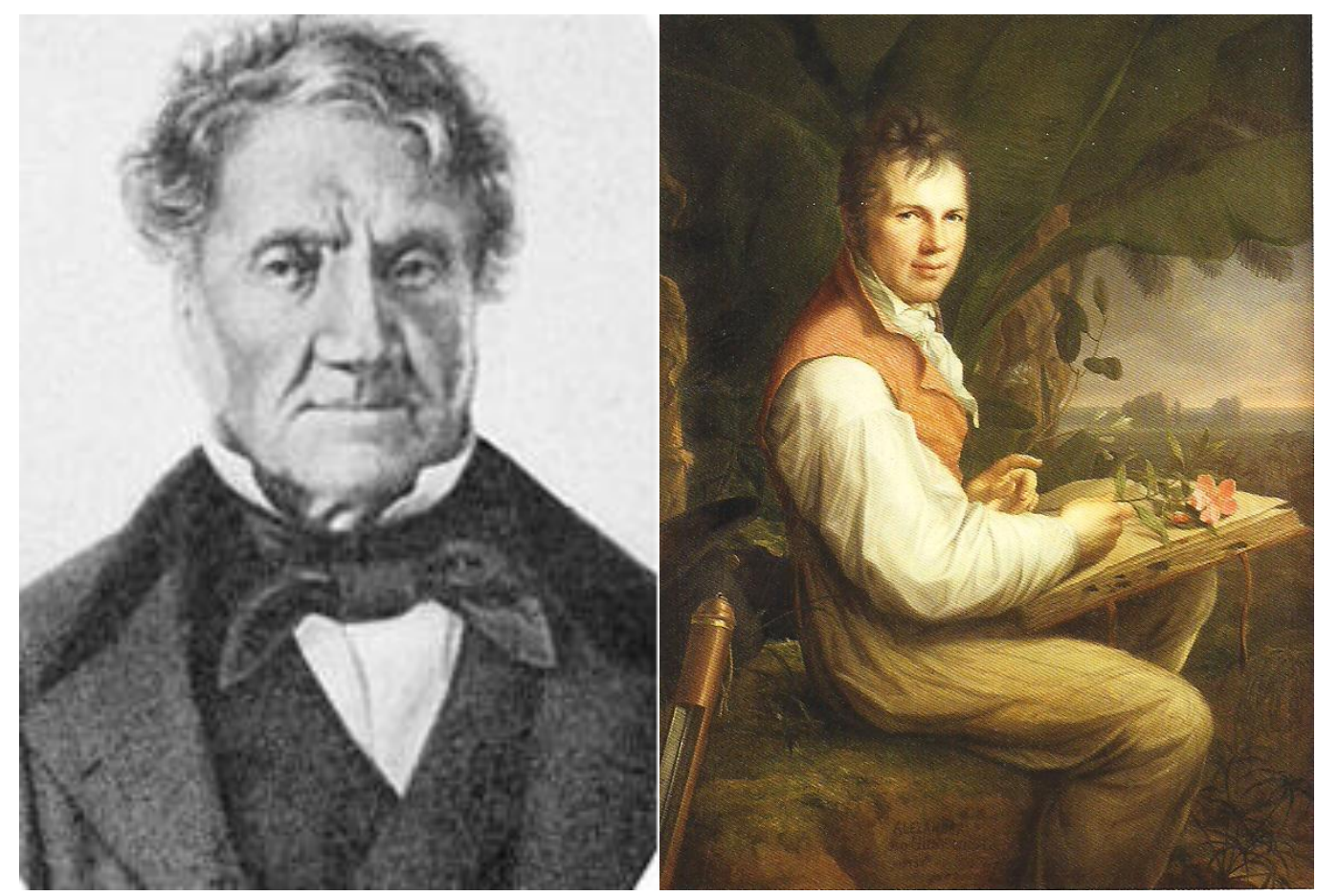

FIGURA 1: (A esquerda) Retrato de Aimé Bonpland (A direita) Friedrich Georg Weitsch, Retrato de Alexander Von Humboldt por Friedrich Georg Weitsch1806, óleo s. tela, 126x92,5 cm.

Fonte: BÖING, 2014

Retornando à Europa em 1804, a fim de publicar suas descobertas. Eles entregaram ao Jardim Botânico de Paris, um herbário composto por (60.000) sessenta mil espécies, com (3.600) três mil e seiscentas delas desconhecidas. Por conta disso receberam tributos de reconhecimento e uma pensão do governo francês. Na época, no final do século a expedição foi um grande desafio e um exemplo único na história.

Esse trabalho foi descrito através de três volumes introduzindo os europeus nessa terra antes misteriosa. De acordo com Martin Rix (2014) os resultados dessa expedição foram escritos em 30 volumes intitulados Les Voyage Aux Régions Équinocxiales Du Nouveau Continent. Ricamente ilustrado por Pointeau e Turpin. 


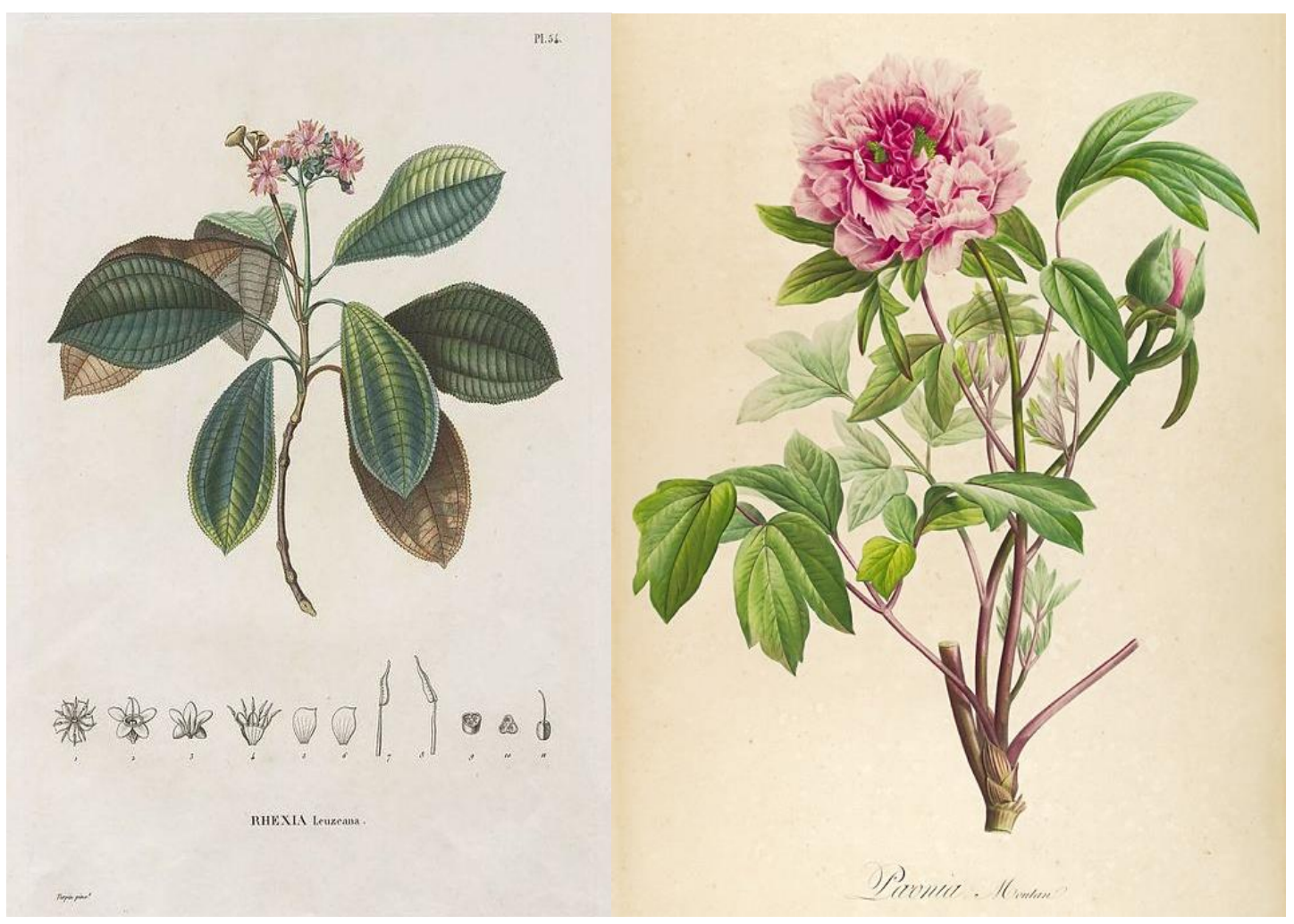

FIGURA 2: (A esquerda) do livro Les Voyage Aux Régions Équinocxiales Du Nouveau Continent. (A direita) Ilustração de Peonea do livro Descriptionsdes plantes rarescultivées à Malmaison et à Navarre

Em Paris, Bonpland tornou-se conhecido, motivo pelo qual a Imperatriz o chamou para o Palácio Malmaison, tornando-se um botânico e intendente real.No tempo em que esteve na França Bonpland envolveu-se em mais duas publicações importantes:Monographiedes Melastomes (1806)e Descriptionsdes plantes rarescultivées à Malmaison et à Navarre.

RIX (2014) destaca que esse período em que esteve na França, o botânico trabalhou para a imperatriz Josefina (1763-1814) a qual cultivava um lindo jardim com rosas e outras plantas, desse período resultou a publicação de um livro, intitulado Descriptionsdes plantes rarescultivées à Malmaison et à Navarre (Descrição das plantas raras e cultivadas em Malmaison e em Navarra). Com texto de Aimé Bonpland e ilustrações produzidas por PierreJoséph Redouté (1759-1840) e Pancrace Bessa (1772-1846). 
Bonpland e Humboldt seguiram caminhos diferentes, enquanto Humboldt permaneceu na Europa escrevendo e publicando os resultados da expedição. Bonpland regressa a América do Sul em 1816, trazendo em sua bagagem uma infinidade de semente sonhando em fundar um jardim botânico. Inicialmente instalou-se em Buenos Aires onde passou a exercer a profissão de médico, e também a colaborar com periódicos locais em questões ligadas às ciências naturais, dividindo seu tempo entre o exercício da medicina e o coletar de espécies vegetais raras.

Com a morte de Josefina, os herdeiros não tinham mais interesse em manter Bonpland em Malmaison, e o médico buscou alternativas para refazer sua vida. Na América do Sul, havia a amizade de Simon Bolívar, com quem conviveu na Europa, e o convite de Buenos Aires para organizar um museu de história natural. Ele escolhe a Argentina, onde aporta em janeiro de 1817, ao lado da mulher, Adelia Bouchy, e da enteada, Emma. (Gaucha $\mathrm{ZH}, 2020)$

Alguns fatores contribuíram para um novo direcionamento na vida do aventureiro. Dentre eles, vale destacar a situação política que o impediu que seu sonho de fundar um jardim botânico e o rompimento do casamento com Adelia.

Como naturalista buscou compreender também a erva-mate, que nortearia toda sua trajetória adiante. Ao encontrar vestígios do cultivo de erva-mate pelos Jesuítas, Bonpland se interessa em estudar a planta. Em 1820 se instalou em Santa Ana na Argentina, antiga redução jesuítica da província de Missiones, ignorando que a produção e comércio da ervamate era monopólio do Paraguai que mantinha conflitos de limites com a Província argentina de Corrientes pela possessão das Missiones.

Bonpland chegou ao Rio da Prata quase no final de 1816, trazendo consigo vasta bagagem que incluía sementes e duas mil plantas vivas." As expectativas da elite de Buenos Aires quanto ao que ele poderia realizar eram enormes, entre elas a idéia de que seria capaz de introduzir novos métodos de agricultura prática baseados em suas observações na Inglaterra, França e América. O cientista logo se engajou num reconhecimento botânico da região de Buenos Aires. No fim do ano de 1818, ao investigar a ilha próxima de Martín García, suas descobertas incluíram o que restava do mate cultivado pelos jesuítas; estes haviam plantado pés de mate aos milhares em suas missões do Alto Prata.' Esse chá verde, elemento básico na dieta dos habitantes da região, parece ter instigado a imaginação de Bonpland. O caráter científico e o potencial comercial do mate tornaram-se preocupações primordiais pelo resto de sua vida. (STEPHEN, 1992. p.67)

O paradigma europeu de progresso viu na erva mate uma importante riqueza comercial. O conhecimento técnico e cientifico de Bonpland, possibilitou a o cultivo de ervais, tão fundamentais ao crescimento econômico na época. As sementes eram protegidas 
por um maciço, Bonpland estudou técnicas de germinação possibilitando o cultivo de ervais de forma independente do ciclo natural da planta.

O naturalista ignorava que a produção e comércio da erva-mate era monopólio no Paraguai que mantinha conflitos de limites com a Província argentina de Corrientes pela possessão das Missiones. Este fato intensificou a hostilidade em relação a suas pesquisas sobre a erva-mate levando a destruição de suas plantações. Em uma invasão de soldados paraguaios, na estância de Santa Ana, Bonpland foi ferido e levado para a margem direita do Rio Paraná, permanecendo aprisionado na aldeia de Santa Maria de Fé durante nove anos.

Durante a prisão, Bonpland circulava livremente por Santa Maria, mas não podia deixar a cidade. Ali, exerceu a medicina e se tornou um habitante estimado. Autoridades de diferentes países intercederam pela soltura, sem sucesso. Foi só em 1831 que o francês foi libertado. Contava então 58 anos, uma idade adiantada para a época. Mas, naquele momento, ele recém iniciava uma nova vida - ainda casaria, teria três filhos e batalharia pelo cultivo da erva-mate em mais um país, o Brasil.

(Gaucha ZH, 2020)

Seus amigos e admiradores exerceram toda a sua influência para devolver-lhe à liberdade.

\footnotetext{
Entre os viajantes, um em especial se dedicou no empreendimento ervateiro, Aimé Bonpland, também conhecido como Dom Amado. Ele possuía vasta experiência no cultivo de ervais. Em sua fazenda na região de Santa Ana (Argentina), Bonpland cultivou sistematicamente até ser interrompido pelo governo Paraguaio, que o acusou de espionagem. Devido a isso, Dom Amado teve seus ervais destruídos e permaneceu preso cerca de uma década. Após ser liberto por Rodrigues Francia, no ano de 1831, Aimé Bonpland foi extraditado para a Província do Rio Grande do Sul, onde residiu cerca de 20 anos. (AMARAL, 2003)
}

Em 1831, liberto da prisão, Bonpland se estabelece em São Borja em 1831, uma povoação fundada em torno de uma antiga missão jesuítica as margens brasileiras do Rio Uruguai. Ao instalar-se em São Borja, manda vir seus livros de Buenos Aires, contrata peões e inicia uma nova plantação de erva, e uma criação de ovelhas. Em São Borja passa também a atender como médico, fundou um pequeno hospital de campanha, foi lá que conheceu Vitoriana Cristaldo mulher com quem se casou e teve a filha Carmem, a filha que lhe acompanha até os dias finais.

Bonpland ficou conhecido por seus escritos e descrições de plantas classificadas como "úteis", dando ênfase as suas finalidades. Enquanto os demais coletavam elementos que eram estudados posteriormente na Europa, ele se diferencia ao realizar estudos, enquanto residente estabelece viagens por um longo período, observando mais detalhadamente, principalmente 
plantas e suas utilidades, sendo responsável pela catalogação de diferentes espécies como a erva-mate, araucárias e plantas medicinais.

Em Porto Alegre Bonpland permaneceu três meses e quatro dias, como ele anotou em seu diário. Ao longo desse tempo ele visitou todo esse tipo de empreendimento, anotando detalhadamente os procedimentos envolvidos na fabricação de velas, de sabão, de queijos dos Alpes e, também, de cápsulas de copaíbas, cal, vinagre de vinho, lixívia, sabão medicinal etc. (AMARAL, 2003, p.279)

Em 1978, Dr. Alicia Louteig transcreveu um manuscrito original de Aimé Bonpland intitulado Voyage de Sn. Borja a La Cierra y a Porto Alegre, trazendo contribuições valiosas sobre muitos aspectos principalmente sobre a vegetação. Através de algumas passagens, podemos perceber a forte relação de toca que Bonpland estabelecia com comerciantes e residentes, que em muitos momentos lhe enviavam amostras de plantas para serem analisadas.

Em maio de 1831. Vi duas plantas dessa espécie ainda não desenvolvidas e cujo estróbilo ainda estava coberto de escamas. A anatomia que fiz dessa planta rara me fez conhecer apenas amenta masculina. Descrevi sob o $n^{\circ} 1043$ esta planta pretensiosa e bastante incompleta como a coloquei nas Coníferas? e considerou um novo gênero. Esta planta foi apanhada por um comerciante de Sn Borja (Dn Bernardo Sarrato), próximo ao pequeno rio de Sta Lucia, na beira da floresta que faz fronteira com o Uruguai, que deu a planta a Dn Juan Palmer, que deu para mim. Desde agora até hoje, ou seja, por seis anos consecutivos, não parei de fazer pesquisas sobre essa planta curiosa e é apenas por alguns dias que sou capaz de conhecer positivamente sua localidade e as estude e descreva-o de maneira exata. (BONPLAND, 1849, p.140)

A convivência com colonizadores imigrantes e índios favorecia o desenvolvimento de seus estudos, através da troca de informações com as pessoas da região sobre as plantas. Mesmo que ocupando-se com a comercialização, Bonpland dedicava boa parte do seu tempo a estudos detalhados de espécies de plantas e animais.Os relatos são ricamente detalhados com informações do local de coleta, características botânicas, muitas vezes apontam sugestões de uso comercial ou medicinal.

\footnotetext{
Além disso, ao longo desta semana, estive ocupado desenhando as raízes do convólvulo descrito sob o $\mathrm{n}^{\circ} 2336$ da terra, convencido de que suas raízes tuberosas lhe conferem leite espesso que muda muito rapidamente ao entrar em contato com o ar uma resina, goma de cor amarela ou preta brilhante oferecerá ao medicamento um novo purgativo útil. (BONPLAND, 1849, p.24)
}

Em 1850, muda-se definitivamente para Santa Ana na Argentina de onde continua a fazer o trajeto até São Borja. Sempre que possível Bonpland coletava espécies que eram enviados a Europa ou a Buenos Aires, visando enriquecer o Museu de Ciências Naturais. 
Sua paixão por este continente enxergado como exuberante, rico e virgem o levou a regressar e permanecer nele até sua morte. Mas esta escolha aparentemente idílica foi também uma opção política. Enquanto Humboldt re-inventava a América no Velho Mundo, Bonpland achou mais conveniente se inserir na sociedade latinoamericana, renovada após os movimentos revolucionários de inícios do século XIX. Para Bonpland, o novo não estava no discurso, na escrita "sobre" a América, senão na ação "na" América. Daí sua estratégia de se aliar às novas elites crioulas que surgiam, se enfrentavam, consolidavam e morriam nesse novo contexto político de formação das nações latino-americanas. Talvez o olhar de Bonpland fosse um tanto utópico ao não dimensionar as divisões destas elites, como suas lutas para impor o poder hegemônico de umas sobre outras. Bonpland participou neste universo de rivalidades, mas geralmente do lado daqueles que foram derrotados. Isso traduziu-se não só em solidão e empobrecimento material, senão também na não transcendência política de Aimé, que era uma de suas ambições não declaradas. Enquanto a trajetória de Humboldt é recuperada até hoje não só por seus estudos acadêmicos senão também pela transcendência econômica e políticas destes, Bonpland só é lembrado como um dos principais botânicos de sua época, caindo no esquecimento total sua ativa participação política na América do Sul. (MOREIRA e QUINTEROS, 2008 p. 232)

Luiz Antônio de Assis Brasil (2012), escritor que se inspirou na história de Bonpland para escrever o romance "Figura a Sombra", destaca que "Bonpland teve uma importância espantosa para a disseminação da história natural no Cone Sul. Criou e ajudou a consolidar instituições, foi um sujeito dedicadíssimo. Além disso, recuperou as técnicas de cultivo de ervamate dos jesuítas". 


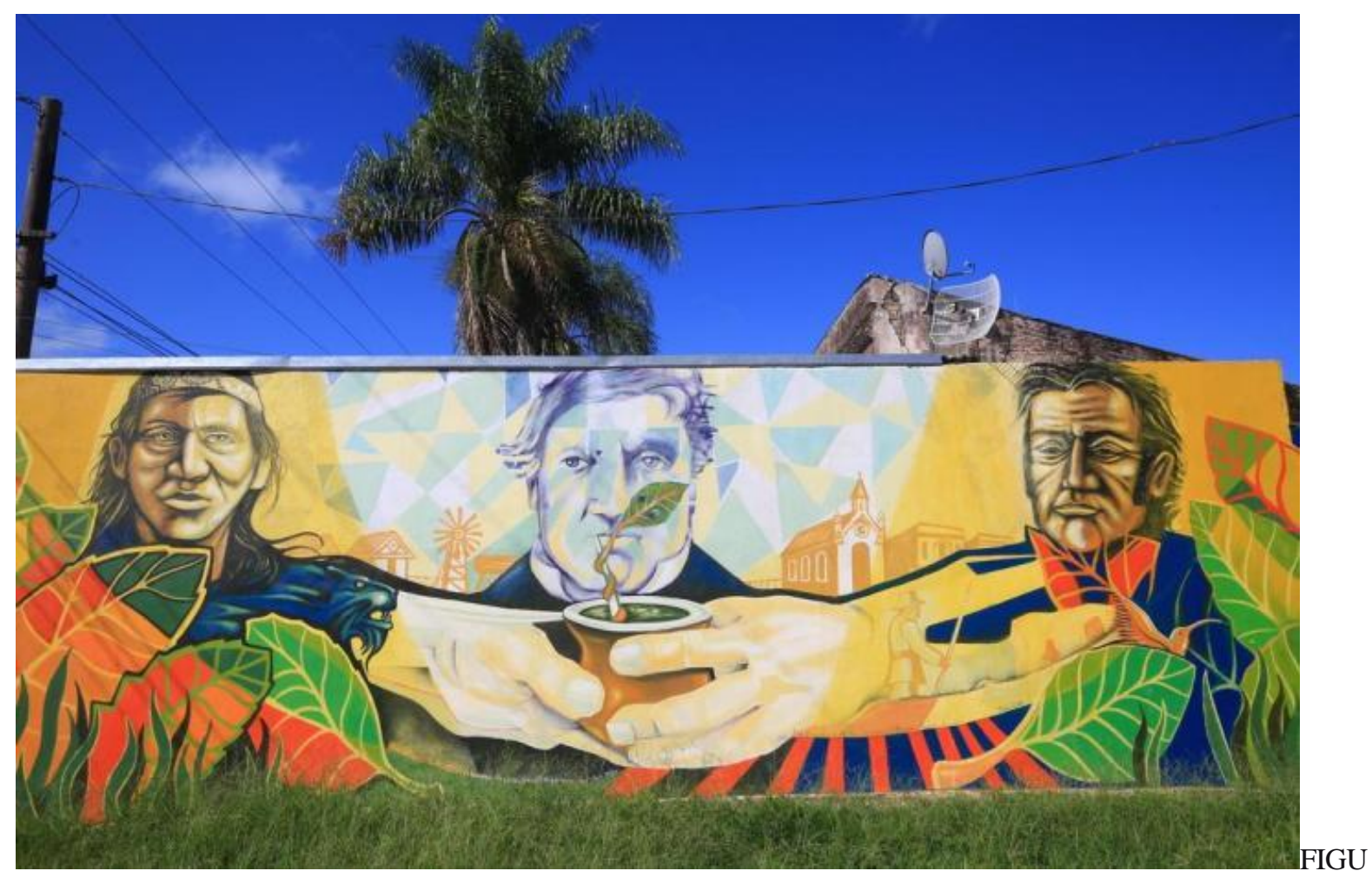

RA 3: Mural erguido na cidade argentina que leva seu nome, Bonpland aparece entre o general Artigas (D), líder da libertação uruguaia, e o herói indígena Andresito

FONTE: Gaucha ZH - Tadeu Vilani Agencia RBS

Conhecido como Amado Bonpland, veio a falecer em 1858 na localidade de Santa Ana em Corrientes atualmente conhecida como Bonpland em homenagem ao naturalista. Naquela região permaneceram seus descendentes, o que colabora para que a memória de Bonpland seja mais preservada no país vizinho. Logo na entrada da cidade argentina, que conta com pouco mais de mil habitantes, há um painel grafitado com a imagem de Bonpland tomando mate (Figura 3). Um pouco mais adiante, há um busto do francês, além de outras referências espalhadas pelo pequeno bairro central.

\section{Considerações Finais}

A figura enigmática de Aimé Bonpland desperta curiosidade e instiga inúmeros pesquisadores que buscam compreender suas contribuições para a ciência e os motivos que o levaram a escolha por uma vida de reclusão. Dentre os pontos que se destacam na sua trajetória ficam bastante evidentes sua parceria com Alexander Von Humbold, a relação com a Imperatriz Josefina e obsessão pela erva-mate. 
Conhecer a trajetória de vida de Aimé Bonpland nos permite reconhecer e investigar suas contribuições no desenvolvimento da ciência moderna na América do Sul sobre tudo no Rio Grande do Sul, como suas grandiosas coleta e descrições botânicas ainda hoje estudadas por cientistas do mundo todo.

\section{Referências}

AMARAL, Marise Basso. Histórias de viagem e a produção cultural da natureza: a paisagem do Rio Grande do Sul segundo os viajantes estrangeiros do século XIX.Porto Alegre: UFRGS, 2003.

ASSIS BRASIL, Luiz Antonio de. Figura na sombra. Porto Alegre: L\&PM, 2012

BERND, Zilá. Figura na sombra ou AiméBonpland Habitando a Distância e o Esquecimento. UFRGS/Unilasalle S/A.2013.

BONPLAND, Aimé. Diário: viagem de São Borja a Serra de Porto Alegre. Transcrição por Alicia Lourteing; Paris: 1978

ECKERT, José. P. O Povo dos Ervais - Entre o Extrativismo e a Colonização (Santa Cruz 1850-1890) Dissertação De Mestrado Unissinos: 2001. p, 106

FRY, Carolyns. Os caçadores de plantas: as aventuras dos maiores exploradores botânicos do mundo. (Trad.) Eduduardo Gomes Gonçalves. São Paulo. Editora Europa 2014.

KURY, L. Viajantes Naturalista no Brasil oitocentista: experiência, relato e imagem. História Ciência e Saúde. Manguinhos, Vol II, 2001.

LALLEMANT, Robert Avé-. Viagem pela Província do Rio Grande do Sul. Belo Horizonte. Itatiaia, 1980. P, 239

MOREIRA, Luiz Felipe; QUINTERO, Marcela Cristina. Em busca de AiméBonpland. Fronteira, Dourados, MS, V.10, n.18, p.221-236, jul./dez.2008.

RIX, Martin. A era de ouro da arte botânica. São Paulo, Editora Europa, 2014. 
ROSA, Lilian da. O complexo ervateiro na Província do Rio Grande do Sul oitocentista visto sob as impressões de viajantes. UNICAMP, 2014.

WITKOWSKI, Nicolas. Uma História Sentimental das Ciências - Col. Ciência e Cultura: 2004.

WULF, Andrea. A Invenção da Natureza: a vida e as descobertas de Alexander Von Humboldt. (Trad.) Renato Marques. 2a Ed. São Paulo: Planeta do Brasil, 2019.

20/02/2020.

O sábio francês que quis fazer do chimarrão uma bebida universal. Gaucha $\mathrm{ZH}$, Aimé Bonpland: de prisioneiro no Paraguai a personagem de romance. Gaucha $\mathrm{ZH}$, 28/02/2020. 